\title{
Evidence of Preferential Directions for Gravity Wave Propagation Due to Wind Filtering in the Middle Atmosphere
}

\author{
M. J. TAYLOR ${ }^{1}$ \\ Physics Department and Space Dynamics Laboratory, Utah State University, Logan \\ E. H. RYAN AND T. F. TUAN \\ Physics Department, University of Cincinnati, Ohio
}

R. EDWARDS

Physics Department, The University of Southampton, Southampton, England

\begin{abstract}
All-sky TV images of wave structure in the near-infrared hydroxyl $(\mathrm{OH})$ nightglow emission were recorded over a 3-month period during May, June, and July 1988 from a high-altitude site at the Mountain Research Station $\left(40.0^{\circ} \mathrm{N}, 105.6^{\circ} \mathrm{W}, 3050 \mathrm{~m}\right)$, near Nederland, Colorado. Well-defined, coherent wave patterns associated with the passage of short period $(<1$ hour) gravity waves were observed on a total of 22 occasions. The wave motions exhibited similar spatial and temporal properties during each month but a distinct tendency for northward propagation (68\% of the wave azimuths within $\pm 40.0^{\circ} \mathrm{N}$ ), with some eastward motion in May and June, was observed throughout the campaign. Although it is theoretically well known that upward propagating gravity waves can be blocked at a critical layer produced by the interaction of the waves with the horizontal background wind, observational evidence of this phenomenon is rare. To investigate the possibility that the asymmetry in the wave propagation directions was caused by the critical layer, a model based on mean climatological background winds and numerical tidal wave modes valid for any mid-latitude site and time of the year was constructed to show the regions forbidden to upward gravity wave propagation from critical layer theory. These "blocking diagrams" which vary with height and time were constructed for the $\mathrm{OH}$ altitude $(\sim 87 \mathrm{~km})$ for the present paper. Comparison of the predicted (i.e., least restricted) and the observed directions of the wave motion show almost complete agreement. This suggests that middle atmospheric winds can play an important role in determining the flux and the azimuthal distribution of short-period waves reaching the upper atmosphere.
\end{abstract}

\section{INTRODUCTION}

In recent years the importance of small-scale, short-period gravity waves on the dynamics of the upper atmospheric circulation has been recognized [Fritts and Vincent, 1987]. Observations of the bright infrared hydroxyl $(\mathrm{OH})$ Meinel band emissions, which originate from a well-defined layer centered at an altitude of $\sim 87 \mathrm{~km}$ [Baker and Stair, 1988], have proved most useful for investigating these waves.

Initially, the properties of the short-period waves were difficult to determine using spectrometric and single-point photographic measurements. Indeed it was not until Peterson and Kieffaber [1973] obtained photographic evidence of wavelike structure at near-infrared (NIR) wavelengths that their true extent was first appreciated. Since then there have been several photographic and low light TV investigations of wave structure in the NIR OH and other nightglow emissions at high, medium, and low latitudes (see, for example, Moreels and Herse [1977], Crawford et al. [1978], Peterson [1979], Hapgood and Taylor [1982], Herse [1984], Clairemidi et al. [1985], Armstrong [1986], Adams et al. [1988], Taylor

\footnotetext{
${ }^{1}$ Previously at Physics Department, The University of Southampton, Southampton, England.
}

Copyright 1993 by the American Geophysical Union.

Paper number 92JA02604.

0148-0227/93/92JA-02604\$05.00 et al. [1987, 1991a, b], Taylor and Henriksen [1989], and Taylor and Hill [1991]).

Low light images of the nightglow emissions provide an excellent method for remote sensing the two-dimensional spatial and temporal evolution of short-period wave motions over a large geographic area and with a high temporal resolution [Taylor et al., 1987]. The data give important information on the occurrence frequency, horizontal wavelengths, and apparent horizontal phase velocities of the wave perturbation. These facts together with the geographical location, shape, orientation, and time of the displays have been most helpful in investigating potential wave sources [Taylor and Hapgood, 1988; Taylor and Edwards, 1991], many of which are thought to originate in the lower atmosphere.

Several attempts have been made in the past to associate various upper atmospheric wave phenomena with meteorological disturbances (see, for example, Hines [1968], Krassovsky and Shagaev [1977], Röttger [1977], Freund and Jacka [1979], Hung et al. [1979], Chiu and Sharp [1981], Gavrilov and Shved [1982], Taylor and Hapgood [1988], and Taylor and Edwards [1991]). However, for various reasons, only a few of these investigations have succeeded in positively identifying individual wave sources.

To investigate the gravity wave morphology over an extended time interval, a series of measurements were recorded over 3 consecutive months during May, June, and 
July 1988. The observations were made as part of the Middle Atmosphere Periodic Structure and Associated Radiance (MAPSTAR) program and revealed similar spatial and temporal properties for the wave displays observed during each month, but a distinct tendency toward preferential directions of motion which varied from month to month was noted. The apparent asymmetry in the propagation headings of the gravity waves is due to the presence of critical layers which can occur at any height level where the horizontal wind velocity along the direction of the horizontal wave vector equals the horizontal phase velocity and the intrinsic frequency is Doppler-shifted to zero. At the critical layer height a horizontal surface region can be constructed to give a polar plot (a "blocking diagram") showing the range of azimuthal angles and speeds of gravity waves forbidden from further upward propagation [Ryan, 1991; Ryan and Tuan, 1991]. Gravity waves with horizontal phase speeds and directions within this region would encounter heavy absorption from a large number of diverse and relatively unstructured mechanisms [Booker and Bretherton, 1967; Hazel, 1967; Jones, 1968; Fritts and Geller, 1976; Fritts, 1978, 1979; He et al., 1990, 1991] as they approach the critical layer. Gravity waves with horizontal phase velocities outside this region would not encounter a critical layer and should be observable.

In the absence of detailed simultaneous wind measurements we have first constructed a model of the zonal and meridional wind profiles for each month using the latest climatological information [Forbes, 1982a, b; Forbes and Gillette, 1982; Barnett and Corney, 1985; Fleming et al., 1988; Fleming and Chandra, 1989; Forbes and Vial, 1989; Chandra et al., 1990]. This model gives the mean wind profile for any geographic location and month of year from which we then construct the blocking diagrams just mentioned. In this paper we discuss the construction of the wind profiles and show how the blocking diagrams are computed for a given site, height, and time of the year (hour of the day and month). The results of the protracted $\mathrm{OH}$ image measurements are then compared with the model calculations to investigate the effects of wind filtering on the propagation of short-period gravity waves into the upper atmosphere.

\section{OH ObSERVATIONS}

All-sky observations of the NIR nightglow emissions were made from the $\mathrm{C} 1$ site of the Mountain Research Station, near Nederland, Colorado $\left(40.0^{\circ} \mathrm{N}, 105.6^{\circ} \mathrm{W}, 3050 \mathrm{~m}\right)$, using a modified Image Isocon TV system capable of obtaining good quality images of wave structure with an integration time of typically 2-5 s [Taylor et al., 1987]. The camera was fitted with a Nikon $8 \mathrm{~mm}, \mathrm{f} / 2.8$ "fish eye" lens and a Schott RG715 filter. The combined response of this filter with the upper wavelength cutoff of the camera tube (type S25) limited the band pass (at half maximum) of the observations to $715-810 \mathrm{~nm}$. This region of the nightglow spectrum is dominated by several $\mathrm{OH}$ Meinel band emissions which have an integrated emission intensity of typically $2.0 \mathrm{kR}$ [Llewellyn et al., 1978]. Wave structure was detectable at all azimuths up to a range of $\sim 600 \mathrm{~km}$ (limited by local horizon) which corresponds to a nominal search area of $\sim 10^{6} \mathrm{~km}^{2}$ (assuming an emission altitude of $87 \mathrm{~km}$ ). Observations were made during three consecutive new moon periods; May 11-22, June 7-22, and July 9-18, 1988. Coherent wave patterns were observed on 22 occasions during this time. Figure 1 shows a good example of a well-defined $\mathrm{OH}$ pattern with near east-west aligned wave fronts extending over the whole camera field. The image was obtained on July 10 at 0510 UT during a "bright night" display [Hoffmeister, 1952] when similar waveforms were also detected in the OI $(557.7$ $\mathrm{nm}$ ) nightglow emission (which originates at $\sim 96-\mathrm{km}$ altitude) [Offermann and Drescher, 1973] and at visible wavelengths by the dark adapted eye. The clarity of the individual structures was best to the north and south of the optical site, but fainter, similarly oriented waveforms were also present in the zenith. The bright band intersecting the wave display at an acute angle is the Milky Way. Some discrete meteorological clouds (dark areas) can be seen at low elevations to the north and west. An increase in sky brightness due to scattered light from cities on the Colorado plains to the east is also evident. Data were obtained for approximately 4 hours this night, but after 0640 UT the recordings were limited by meteorological clouds. During this time the pattern remained extensive and uniform and moved toward the north. The high contrast and large apparent spatial extent of the display imaged on this occasion was quite unusual. Most of the wave patterns recorded during the campaign were less conspicuous and usually appeared as a set of well-formed elongated structures occupying a finite but variable area of the camera field (see Figure 2).

The data have been analyzed to determine the geographic location and orientation of the wave patterns and where possible their horizontal phase speeds. The all-sky images were calibrated in terms of elevation and azimuth using the right ascension and declination of several known stars within the camera field [Hapgood and Taylor, 1982; Lanchester, 1985]. Ground maps showing the position and motion of the waveforms as a function of time were then calculated for each display (assuming an emission altitude of $87 \mathrm{~km}$ ), from which their average horizontal wavelengths and velocities were determined. Figure 2 shows six example maps (two for each month) illustrating the diversity in location, apparent spatial extent, orientation, and motion of the displays. The maps are centered on the mountain research station and show Colorado and adjoining states. Typically several waveforms were detected within the camera field at any one time, but sometimes many more coherent forms were present. The general direction of motion of each display is indicated by the arrows. Only those waveforms that subtended elevations significantly greater than $5^{\circ}$ are plotted.

The results of the image analysis are listed in Table 1 . The azimuth of the wave motions (i.e., the normal to the wave fronts) was determined from the ground maps to an accuracy of about $\pm 5^{\circ}$. This represents the dominant direction of motion of each pattern measured over a time interval of typically 0.5 to 4 hours during the nights (depending upon observing conditions). However, at any given time, individual waveforms often exhibited considerable spread about this direction (see Figure 2). Due to changes in the seeing conditions (particularly in June) it was usually easier to determine the orientation and direction of motion of the wave pattern than it was to accurately measure its speed. Nevertheless, velocity measurements were obtained on 14 of the 22 displays detected during the campaign. Several measurements were made from the ground maps to determine the average speed for each display. The spread in the individual measurements was used to provide an estimate of 


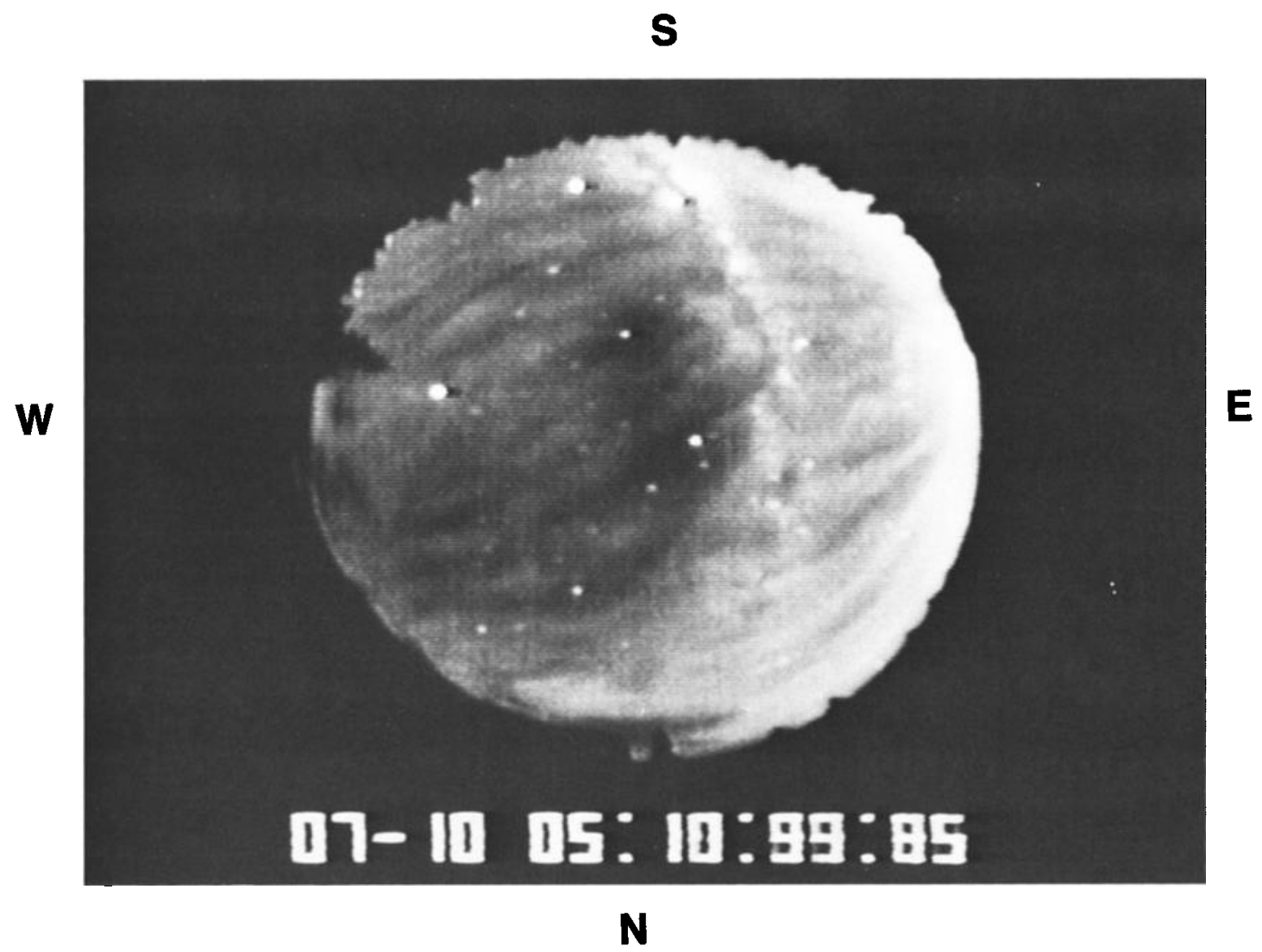

Fig. 1. All-sky image showing coherent near-infrared (NIR) wave structure extending over the whole camera field. Geographic north appears at the bottom of the picture. The data were obtained on July 10 at 0510 UT using an integration time of $1.5 \mathrm{~s}$. Similar waveforms were also imaged in the OI $(557.7 \mathrm{~nm})$ nightglow emission and to the north several bands were visible at low elevation to the dark adapted eye. (Note the dark region near the center of the image is due to a defect in the camera tube.)

the error in each case (see Table 1). On two occasions (June 20-21 and July 12) a second wave motion was also detected during the course of the night and both sets of measurements are reported here. Each month shows a clear preference for wave propagation generally toward the north (in total $68 \%$ of the wave azimuths were within $\pm 40.0^{\circ} \mathrm{N}$ ). In May and June, several displays also exhibited significant eastward motion. In July the northward motion became even more restricted in the azimuth range $\left(83 \%\right.$ within $\pm 30.0^{\circ} \mathrm{N}$ ) with only one exception of a wave pattern moving toward the southeast. In particular none of the displays observed during this campaign exhibited strong westward components of motion.

\section{The Wind Profiles Used}

In the absence of suitable wind measurements we have constructed a model [Ryan, 1991; Ryan and Tuan, 1991] for deriving wind profiles at any site (latitude and longitude) and time (hour of the day and month of the year) using the latest available information on the background winds and the solar diurnal and semidiurnal tides and the lunar semidiurnal tide.

\section{Background Winds and Tidal Oscillations}

To calculate the magnitude and direction of the total wind at any given height, the background wind and three predominant atmospheric tides (solar diurnal (SD), solar semidiurnal (SSD), and lunar semidiurnal (LSD)) were added together in the zonal and meridional directions. Climatological data were used for the background winds and numerical model data for the tidal modes.

$$
\text { total wind }=\text { background }+ \text { tidal wind }
$$

The zonal background wind was obtained from the monthly mean zonal wind tables of Fleming et al. [1988] which are discussed by Fleming and Chandra [1989] and Chandra et al. [1990]. The meridional background winds were calculated from the monthly amplitudes and phases of "wave 1" and "wave 2" of the mean geopotential height given by Barnett and Corney [1985]. This wind component is often termed the meridional geostrophic wind [Fleming et al., 1988]. The sum tidal modes were calculated from tabulated values for their amplitudes and phases using the equation

$$
\text { tidal wind }=\sum_{i} A_{i} \cos \left[\left(\frac{2 \pi}{T_{i}}\right)\left(t-\phi_{i}\right)\right]
$$

where $i$ is summed over each of the SSD, LSD, and SD components and $A_{i}$ is the amplitude, $\phi_{i}$ is the phase, $T_{i}$ is the period of the tide (i.e., 24 hours for SD and 12 hours for SSD and LSD), and $t$ is the local time. The SSD amplitudes and phases were obtained for each month using the Forbes/ Vial Model Tides 1988. This information is available from the NCAR CEDAR Data Base [1990] and is discussed by Forbes and Vial [1989]. The data consist of monthly aver- 

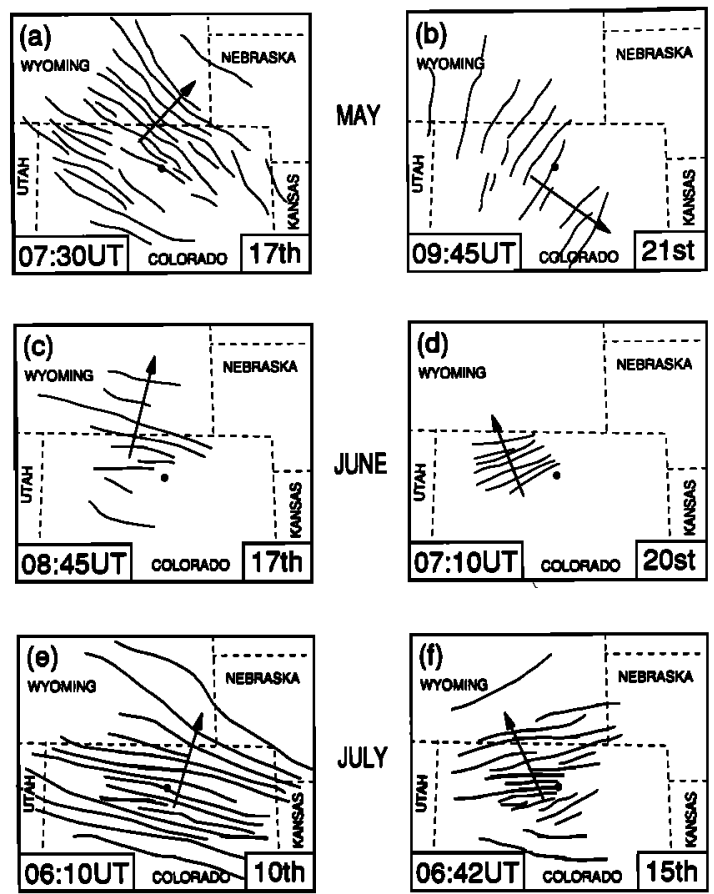

Fig. 2. Ground maps showing the geographic location and orientation of six $\mathrm{OH}$ wave patterns (two for each month). The black spot near the center of each map marks the location of the optical site and the arrows show the direction of motion of the displays. A total of 22 displays were recorded during the campaign. The maps were plotted assuming an emission altitude of $87 \mathrm{~km}$.

ages and is given from latitude $88^{\circ}$ south to $88^{\circ}$ north at $2^{\circ}$ intervals from the ground level to $110 \mathrm{~km}$. Amplitudes and phases for the SD and LSD components are not available on a monthly basis and values for solstice and equinox conditions were used [Forbes, 1982a, b; Forbes and Gillette, 1982]. These tables provide amplitudes and phases from $0^{\circ}$ to $78^{\circ}$ latitude at $6^{\circ}$ intervals from ground level to $400 \mathrm{~km}$.

\section{Analysis of the Cimatological and Numerical Data Model}

The zonal and meridional wind profiles for a given height and geographic site were determined by linear interpolation between the available tabulated values for (1) immediate above and below the height of interest and (2) locations in the immediate surroundings of the site of interest. The tables of wind profiles use different height intervals depending the amplitudes and phases were interpolated separately and the profiles computed from the resultant data points. In the second method the profiles were computed directly using the tabulated data and then interpolated to produce the wind components. As expected, both approaches gave very similar results. Profiles may be computed for any hour of the day and for each month of the year [Ryan, 1991; Ryan and Tuan, 1991].

As the SD and LSD tidal components are only available for equinox and solstice conditions, wind profiles for months such as March and April currently utilize the equinox data, while May and June employ the summer solstice data. It should be noted that the first available data point for the meridional background wind occurs in the stratosphere at 17 $\mathrm{km}$. For the meridional component the highest available data point occurs at $85 \mathrm{~km}$. Since the meridional wind is much less important than the zonal wind and at this height level the tidal components dominate, a linear extrapolation was employed to extend the meridional wind to $100 \mathrm{~km}$.

\section{Wind Profiles for Colorado Campaign 1988}

Wind profiles were computed for the optical site at the Mountain Research Station for May, June, and July at local midnight. Figure 3 shows the total zonal and meridional components for each of these months (dashed curves). For comparison, wind profiles for December are also plotted (solid curve) to illustrate the difference between summer and winter solstice conditions. The zonal profile shows a steady westward wind during the summer months at stratospheric and mesospheric levels with a peak amplitude at $\sim 65 \mathrm{~km}$ increasing from $\sim 30 \mathrm{~m} \mathrm{~s}^{-1}$ in May to greater than $60 \mathrm{~m} \mathrm{~s}^{-1}$ in July. During the winter months the wind reverses direction, creating strong eastward motion of greater than $80 \mathrm{~m}$ $\mathrm{s}^{-1}$ over an extended region in the middle atmosphere.

The meridional wind is strongly influenced by the tidal components and grows significantly in amplitude with height. It is substantially weaker than the zonal wind throughout the middle atmosphere (note the change in horizontal scale for the wind amplitude) and the summer and winter are generally $180^{\circ}$ out of phase with each other due to changes in the tidal oscillations. The contribution of the tidal motions (Figure 4) are not important in the lower atmosphere (below $40 \mathrm{~km}$ ) and they only begin to play a significant role (particularly affecting the meridional winds) at mesospheric heights.

\section{The Model for Critical Level Blocking Diagrams}

\section{The Doppler-Shifted Frequency}

The theory of gravity wave absorption at critical layers is well developed (see, for example, Booker and Bretherton

TABLE 1. Colorado Campaign 1988 OH Data Analysis

\begin{tabular}{lccc}
\hline $\begin{array}{c}\text { Date } \\
\text { UT }\end{array}$ & $\begin{array}{c}\text { Day (UT) } \\
\text { Number } \\
\text { Velocity }\end{array}$ & $\begin{array}{c}\text { Wave } \\
\text { Azimuth } \\
\pm 5^{\circ}\end{array}$ & $\begin{array}{c}\text { Observed } \\
\text { Phase Speed } \\
\text { m/s }\end{array}$ \\
\hline May 13 & 134 & 90 & $30 \pm 2$ \\
May 14 & 135 & 120 & $\ldots$ \\
May 15 & 136 & 0 & $21 \pm 2$ \\
May 16 & 137 & 20 & $28 \pm 2$ \\
May 17 & 138 & 40 & $22 \pm 4$ \\
May 21 & 142 & 125 & $\ldots$ \\
June 9 & 161 & 20 & $\ldots$ \\
June 12 & 164 & 10 & $\cdots$ \\
June 15 & 167 & 0 & $22 \pm 1$ \\
June 16 & 168 & 105 & $\ldots$ \\
June 17 & 169 & 15 & $5 \pm 2$ \\
June 18 & 171 & 55 & $42 \pm 2$ \\
June 20 & $172 \mathrm{a}$ & 15 & $18 \pm 3$ \\
& $172 \mathrm{~b}$ & 340 & $14 \pm 3$ \\
June 21 & $173 \mathrm{a}$ & 80 & $20 \pm 1$ \\
& $173 \mathrm{~b}$ & 20 & $23 \pm 3$ \\
July 10 & 192 & 15 & $\cdots$ \\
July 12 & 194 & 30 & $28 \pm 2$ \\
July 15 & 197 & 335 & $32 \pm 4$ \\
July 16 & 198 & 140 & $37 \pm 3$ \\
July 17 & 199 & 345 & \\
July 18 & 200 & 0 & \\
\hline
\end{tabular}

List of the azimuth of the wave motions (i.e., the normal to the wave fronts) and their observed phase speeds for the 23 displays recorded during the campaign. On two occasions (June 20 and June 21), two wave patterns were observed during the course of the night. 

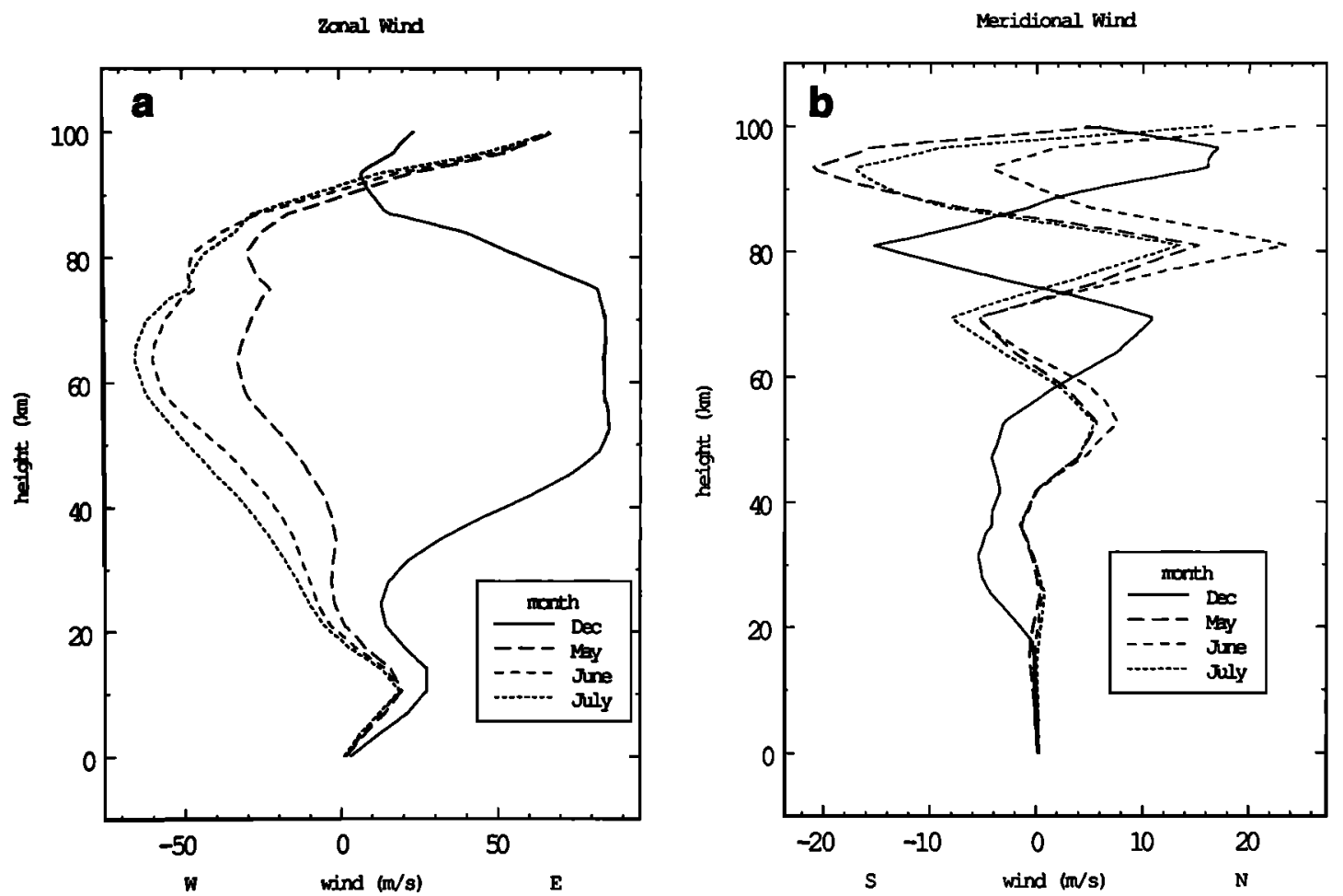

Fig. 3. Model results showing (a) the total zonal wind component and $(b)$ the total meridional wind component as a function of height for December, May, June, and July at local midnight. Note the difference in scales between the zonal and meridional winds. (Unless otherwise stated, all of the plots presented here were computed for the optical site at local midnight (0600 UT).)
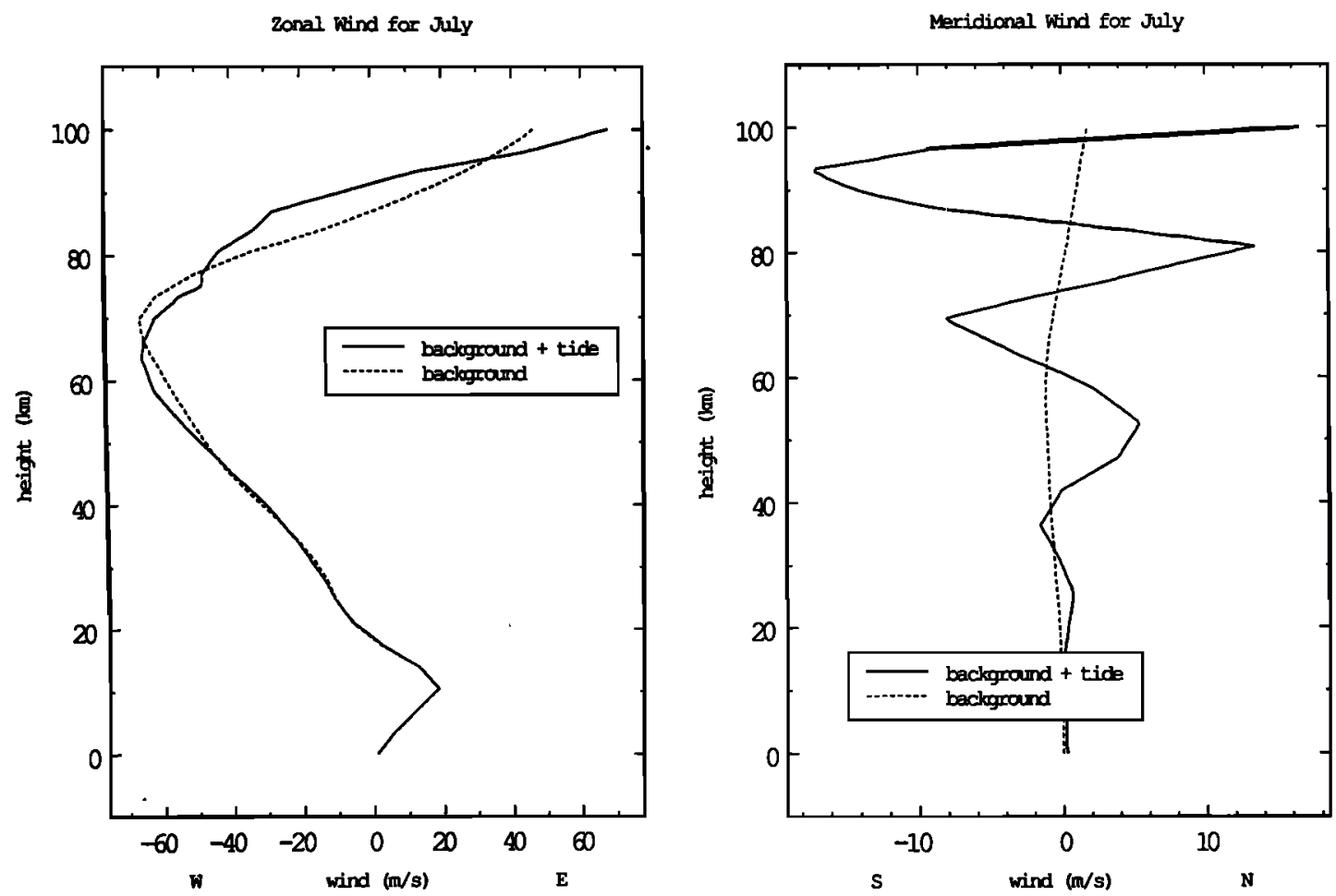

Fig. 4. Zonal and meridional wind plots showing the effect of the sum tidal modes on the total wind component (i.e., background plus tides). The zonal winds are dominated by the background component, but the meridional winds vary significantly with the tidal motions. 


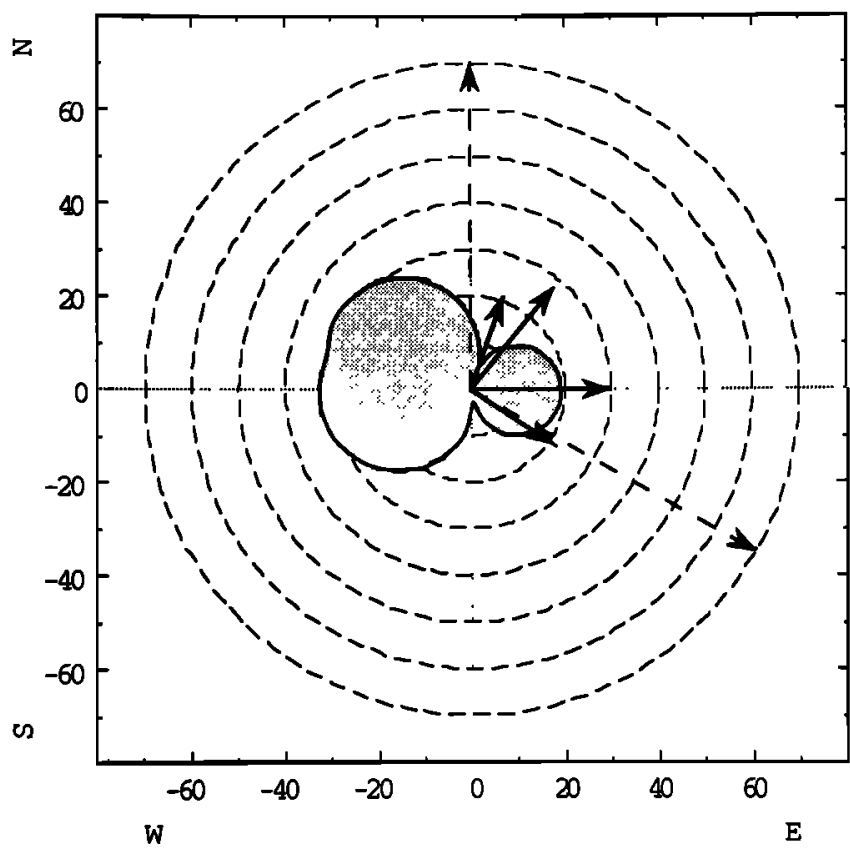

Fig. 5. Blocking diagram for May at $85 \mathrm{~km}$. The shaded area indicates the magnitude and direction of the restricted region for wave propagation to $\mathrm{OH}$ heights. The solid arrows show the magnitude and direction of the wave motions observed during this month, while the dashed arrows indicate direction only.

[1967], Hines and Reddy [1967], Hazel [1967], Jones [1968], Fritts and Geller [1976], Fritts [1978, 1979], and He et al. [1990, 1991]). Gravity waves propagating energy upward from the lower atmosphere are absorbed into the mean flow (and by other mechanisms) as they approach a "critical layer" where the intrinsic frequency of the wave is Dopplershifted to zero. This situation may occur at any height level when the local horizontal wind speed along the direction of propagation equals the observed horizontal phase speed of the gravity wave (which remains constant with altitude). The Doppler-shifted frequency, $\Omega$, due to the horizontal wind $V_{0}$ is given by

$$
\Omega=\omega-k_{x} V_{0 x}
$$

where $\omega$ is the source frequency, $k_{x}$ is the magnitude of the horizontal wave vector, and $V_{0 x}$ is the component of $V_{0}$ along $v_{x}$. Equation (3) can be rewritten as

$$
\Omega=\omega\left(1-\frac{V_{0 x}}{v_{x}}\right)
$$

where $v_{x}$ is the observed horizontal phase speed of the wave. Thus at the critical layer when $V_{0 x} \rightarrow v_{x}, \Omega \rightarrow 0$. Equation (4) can be expressed in terms of the zonal and meridional components as [Wang and Tuan, 1988]

$$
\Omega=\omega\left(1-\frac{V_{z} \cos \phi+V_{m} \sin \phi}{v_{x}}\right)
$$

where $V_{z}$ and $V_{m}$ are the zonal and the meridional wind components.

Equation (5) was used to determine the forbidden regions defined by $\Omega \leq 0$ at any height below the peak of the $\mathrm{OH}$ layer for each propagation direction $\phi$ and phase speed $v_{x}$.
Although downward reflections from any critical layer can be significant [He et al., 1990, 1991], they do not affect the $\mathrm{OH}$ layer if the sources are located in the lower atmosphere. Polar plots (blocking diagrams) with $v_{x}$ as the radius and $\phi$ as the polar angle were then constructed to show which directions and magnitudes are restricted for gravity wave propagation up to $\mathrm{OH}$ altitudes.

Blocking diagrams [Ryan, 1991; Ryan and Tuan, 1991] were plotted for each month using the wind profiles derived for the Colorado optical site. As expected, each plot (see section 5) shows a forbidden region for westward wave propagation due to the strong zonal winds in the stratosphere and lower mesosphere. The blocking effect increases considerably in "area"' from May to July, eventually restricting all westward propagating gravity waves with observed phase speeds below $\sim 65 \mathrm{~m} \mathrm{~s}^{-1}$. Some blocking also occurs to the east during these 3 months. This is mainly due to zonal winds below $20 \mathrm{~km}$ and is much less than the westward blocking. Wave propagation toward the north and south is generally much less restricted. Due to the tidal modes the blocking diagrams can vary at different hours of the day (see Figure 9).

\section{Results}

Figures 5, 6, and 7 show the blocking diagrams for May, June, and July at local midnight for the observation site. The figures were computed for a height of $85 \mathrm{~km}$. This is just below the nominal peak of the $\mathrm{OH}$ emission $(\sim 87 \mathrm{~km}$, half width 5-8 km) and each plot therefore represents the cumulative effects of wave blocking for all heights up to and including the base of the $\mathrm{OH}$ layer. For clarity the restricted regions for wave propagation are indicated by the shaded areas. Superimposed on each of these diagrams are the average horizontal propagation directions and magnitudes

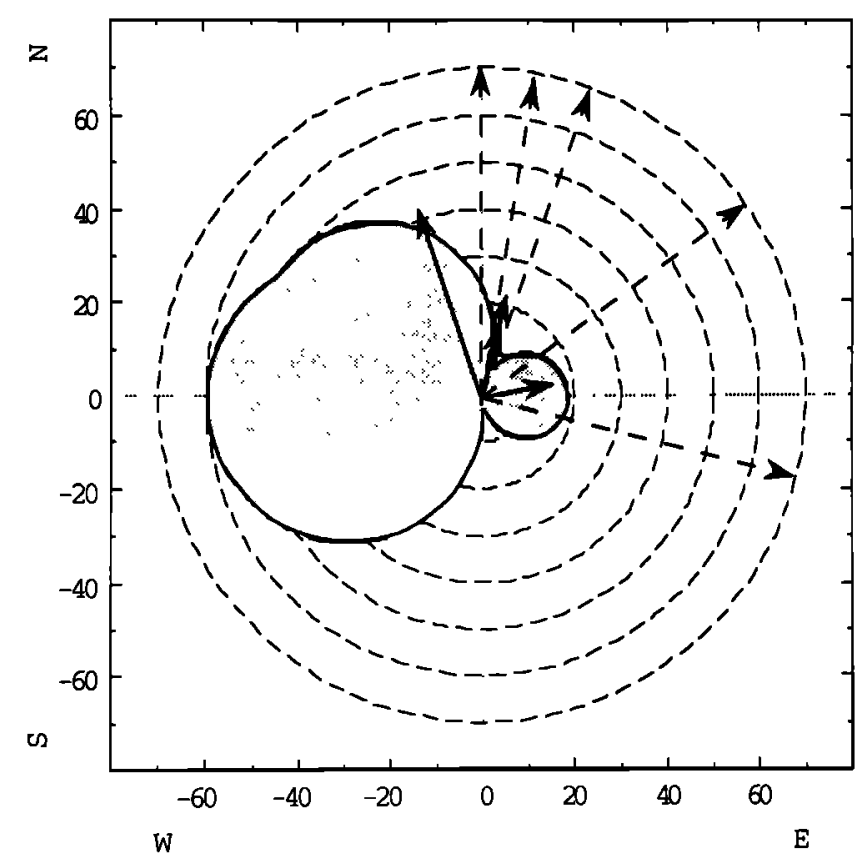

Fig. 6. Blocking diagram for June at $85 \mathrm{~km}$. For comparison the results are plotted on the same scale as Figure 5. Frequent changes in the observing conditions during this month limited the velocity measurements of several displays to direction only. 


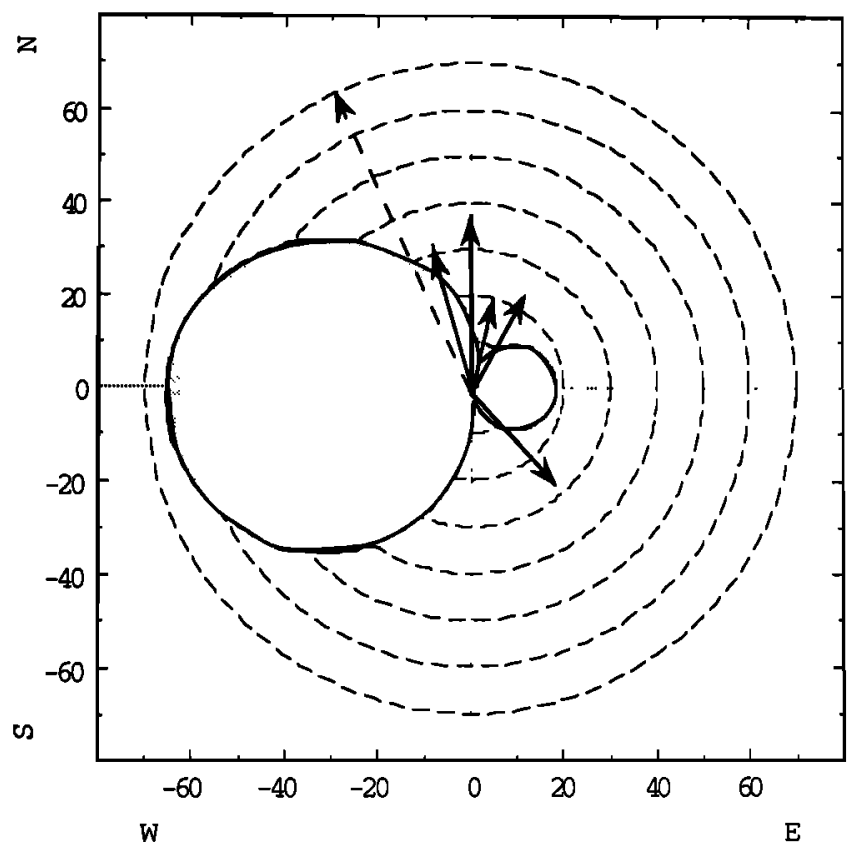

Fig. 7. Blocking diagram for July at $85 \mathrm{~km}$. All but one of the wave patterns observed during this period were restricted in azimuth range to $\pm 30^{\circ} \mathrm{N}$.

(where known) of the 22 wave displays recorded during this period. The solid arrows indicate magnitude and direction of the wave motions, while the dashed arrows show direction only.

In May, six wave displays were recorded and four velocity measurements made (see Table 1). Figure 5 shows that all six wave patterns moved in directions that were least impeded for gravity wave propagation. Moreover, the four measurements of the phase velocity were all in excess of the blocking limits indicating unrestricted wave propagation to $\mathrm{OH}$ altitudes. During June (Figure 6), ten wave patterns were detected, but due to limitations in the observing conditions, only five velocity measurements were possible. Nevertheless, the azimuthal distribution of the patterns were again favorable for wave propagation from the lower atmosphere. One of the displays observed on June 22 (azimuth $80^{\circ}$ ) exhibited a velocity that was apparently insufficient for wave propagation up to $85 \mathrm{~km}$. However, the wave azimuth was clearly directed away from the major blocking region (i.e., almost due east) and the observed phase speed could well have been in excess of the actual blocking limit that existed on this night.

During July (Figure 7) the sky conditions improved considerably and velocity measurements were possible on five of six displays. Remarkably all but one of the wave patterns recorded during this month exhibited well-defined motion towards the north. Moreover the observed phase speeds of the patterns (including the display moving towards the south east) significantly exceeded the nominal blocking limits on each occasion.

\section{Discussion}

The spatial and temporal properties of the wave motions reported here are typical of the mid-latitude nightglow displays described in literature (see, for example, Peterson and
Kieffaber [1973], Moreels and Herse [1977], Armstrong [1986], Taylor et al. [1987]). On occasions these displays have been associated with the passage of short-period $(<1$ hour) gravity waves through the nightglow layers. Although individual sources for the waves have been difficult to locate, there are good reasons why many of the wave sources may be located in the lower atmosphere [Hines, 1960]. In this study all of the wave sources were assumed to be located in the tropospheric regions.

A comparison of the image measurements with the climatological model predictions show almost complete agreement between the predicted (i.e., least restricted) and the observed directions of wave propagation. Furthermore, with only one exception the apparent phase speeds of the waves were always greater than the predicted blocking limits. Thus the waves responsible for the $\mathrm{OH}$ patterns observed during this campaign were probably subjected to considerable directional filtering. The agreement suggests that middle atmospheric winds can play an important role in governing the flux and azimuthal distribution of short-period wave energy reaching the upper atmosphere. As the filtering theory assumes a tropospheric origin for the waves, this study is also consistent with the generally accepted idea of a predominance of lower atmosphere sources at mid-latitudes.

The anisotropy observed in the distribution of wave azimuths is a key element of this study. Assuming the effects of wind filtering were negligible, this result could conceivably have been caused by a nonuniform distribution of sources. This requires that the wave sources were located (1) primarily to the south and west of the optical site during May and June and (2) almost exclusively to the south of the site in July. Moreover, there should have been no similar type sources to the east of the optical site for the duration of the campaign. While the distribution of wave sources during this period was almost certainly not uniform, it is highly improbable that it would have given rise to the observed set of wave motions. As the winds in the middle atmosphere (see Figure 3) can be large compared with the apparent phase speeds of the waves (see Table 1), it is much more likely that the anisotropy in the data resulted from directional filtering of an ensemble of wave motions.

To simplify the investigation the blocking diagrams shown in section 5 were computed assuming that all of the wave sources were located in the vicinity of the optical site. In practice we do not know the actual position of the sources with respect to the observer. In the absence of background winds, gravity waves of a period of $\leq 1$ hour would be expected to propagate from the source region to $\mathrm{OH}$ heights within a ground range of $\sim 800 \mathrm{~km}$ [Freund and Jacka, 1979; Taylor and Hapgood, 1988]. However, as the path of the gravity wave through the atmosphere is strongly dependent upon its intrinsic frequency [Hines, 1960], which changes with the prevailing wind conditions (equation (3)), the horizontal range over which the waves may propagate can be significantly larger. Thus many of the wave motions imaged by the all-sky camera may have originated from sources located several hundred kilometers from the observing site.

To investigate the effects of varying the source location on the blocking diagrams, wind profiles at points $\pm 4^{\circ}$ in latitude and longitude to the north, south, west, and east of the optical site were calculated (corresponding to a change in source position of $890 \mathrm{~km}$ in latitude and $680 \mathrm{~km}$ in longitude). Figure 8 shows the total zonal and meridional wind 

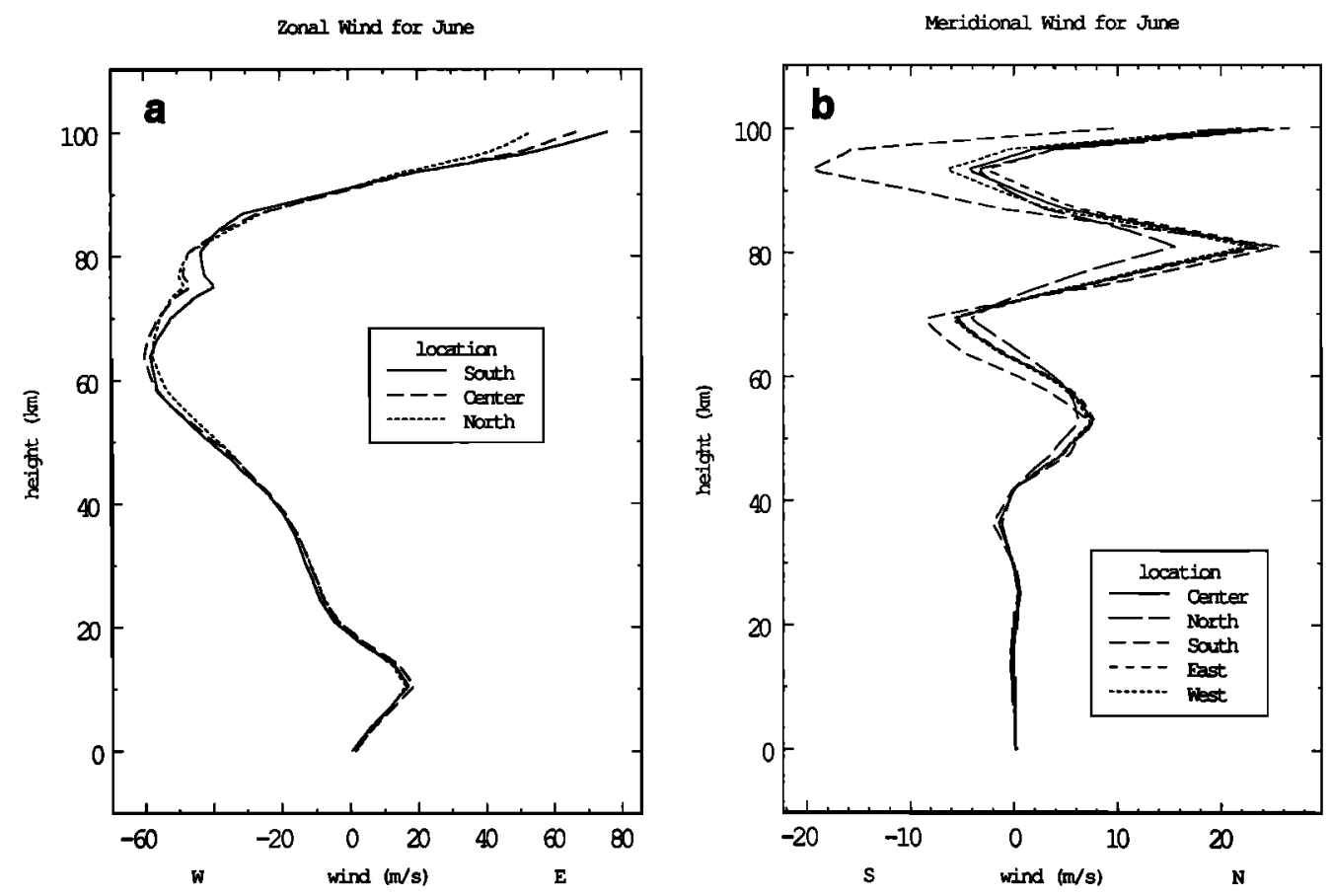

Fig. 8. Model results showing the effect of changing the location of the wind profile calculations on $(a)$ the total zonal and $(b)$ the total meridional components. The data were computed for points $\pm 4^{\circ}$ in latitude and longitude to the north, south, east, and west of the optical site.

components for June. The zonal wind depends solely upon the latitude, and plots are given only for points north and south of the center (optical) site. Some differences between the south and the center/north profiles arise above $60 \mathrm{~km}$ altitude but they are no greater than the changes that take place from June to July (see Figure 3), both of which exhibit similar blocking diagrams (Figures 6 and 7). The meridional winds are more sensitive to variations in source location (e.g., the profile to the south of center), but as the zonal winds dominate, the overall effects on the blocking diagrams are not significant. Thus uncertainties in the location of the wave sources of up to several hundred kilometers appear to have little impact on the net wave filtering. However, sources located at significantly larger ranges may well encounter different wind profiles than those existing at the observing site.

As the wave displays were imaged at different times during the night, changes in the tidal contributions to the wind profiles have also been investigated. This is important as the temporal origin of each wave is not known. For short-period waves the group velocities should be less than the observed phase velocities (i.e., $<50 \mathrm{~m} / \mathrm{s}$, see Table 1), and propagation times of a few to several hours would be expected [Taylor and Hapgood, 1988]. To examine the effect of time changes on the blocking areas, the total zonal and meridional wind components were plotted at 1-hour intervals over the period 0400 to 0900 UT when most of the data were recorded (2200 to $0300 \mathrm{LT}$ ). As expected, the zonal winds showed minimal changes, but the meridional winds varied substantially. Figure 9 illustrates the changes in wave blocking that can occur. The diagrams are plotted for June at 2200 and 0200 LT. The net effect of the tidal variations appears to be a clockwise expansion of the major (western) blocking sector. A similar trend was also found for May and July. During the winter months a counterclockwise rotation of the blocking area from 1000 to $0200 \mathrm{LT}$ occurs. In general, the short-term effects of the tidal mode changes on the blocking diagrams were greater than those induced by variations in the source location. Changes in the blocking area during the course of the night (see Figure 9) may therefore affect the propagation of some waves (particularly those moving northward), but there are no obvious signs of this in our (limited) data set.

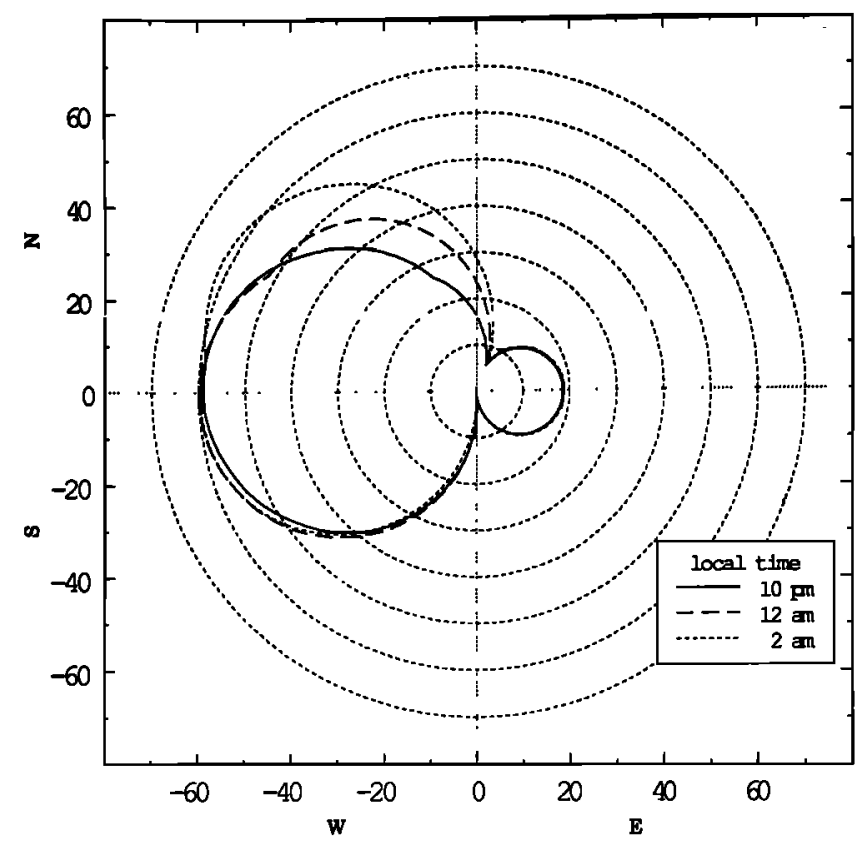

Fig. 9. Blocking diagrams for June at $85 \mathrm{~km}$ showing the shortterm effects of tidal mode changes on the location of the restricted areas for wave propagation. Three local times are shown corresponding to 0400,0600 , and $0800 \mathrm{UT}$. 


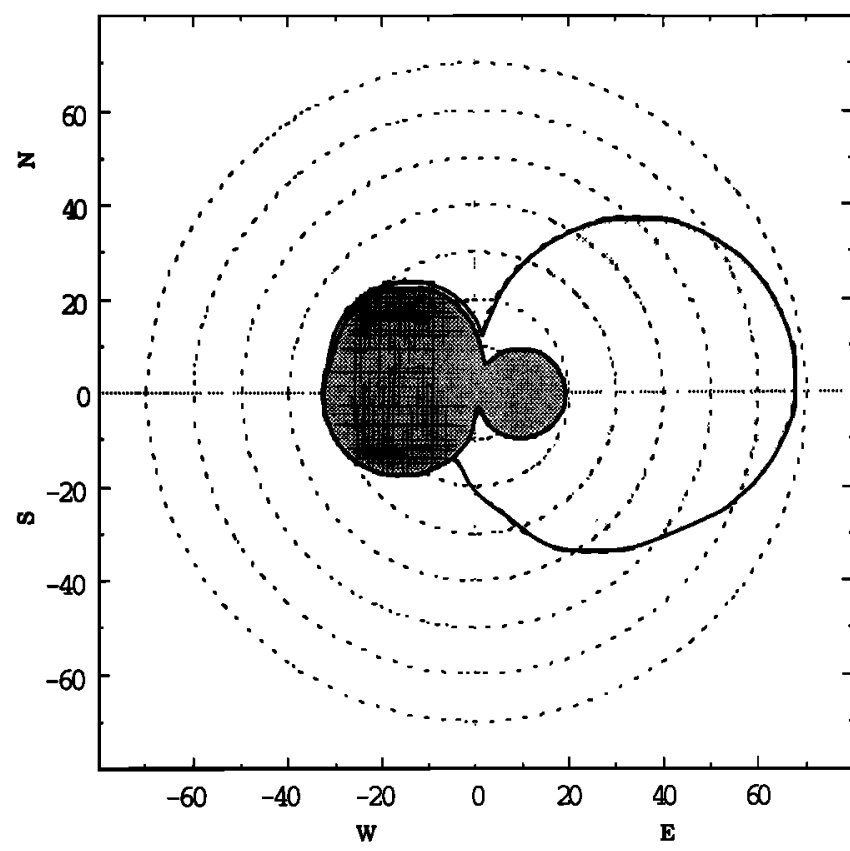

Fig. 10. Blocking diagrams for May showing the effect of changing the height of the investigation on the location and shape of the restricted areas. Two height levels at 80 and $100 \mathrm{~km}$ are shown. The $80-\mathrm{km}$ plot (dark shaded area) is very similar to that of Figure 5. However, the $100-\mathrm{km}$ plot (light shaded area) shows a marked increase in the blocking area to the east. Any waves propagating upward toward the east at $\mathrm{OH}$ altitudes will be strongly filtered before they reach this height.

The filtering of a gravity wave by its absorption into the mean flow at a critical layer applies only when the background winds through which the wave is propagating are stable (i.e., when the Richardson's number, $R i$, of the background medium is significantly greater than $1 / 4)$. Wind profiles exhibiting very steep vertical gradients $(R i<1 / 4)$ are naturally unstable and reradiation or overreflection of the gravity wave can occur [Jones, 1968; Fritts, 1978; He et al., 1991]. Under these circumstances the effect of the wind filtering on the gravity waves needs to be reassessed. An examination of a large number of climatological data on background winds and atmospheric tides has yielded little evidence for such steep vertical gradients. Nevertheless, it is quite possible that a chance combination of background winds with other long-period gravity waves may induce localized regions of instability into the real wind profile. However, the overall agreement between the critical layer theory and the nightglow observations presented here suggest that the occurrence of unstable background winds may be relatively rare.

Figure 10 illustrates the effect of changing the altitude of the blocking investigation. Two heights, 80 and $100 \mathrm{~km}$, are plotted showing the changes in the blocked areas for the optical site at local midnight during May. As discussed earlier, below $90 \mathrm{~km}$, most of the blocking occurs for westward propagating waves. However, above $90 \mathrm{~km}$, strong blocking occurs for both eastward and westward propagating waves. Similar results were obtained during June and July. For comparison the blocking diagrams for winter solstice conditions (December) were also plotted. These plots (not shown) indicate major blocking for eastward wave motion for altitudes up to $100 \mathrm{~km}$. Unlike the summer plots, the winter blocking diagrams remain virtually unchanged over the height range 80 to $100 \mathrm{~km}$. On several occasions, during July, similar wave patterns were imaged in the $\mathrm{OH}$ and $\mathrm{OI}(557.7 \mathrm{~nm})$ green line emission (peak altitude $\sim 96 \mathrm{~km}$ ). Depending upon the azimuth of the wave motions, it is possible that gravity waves seen in the $\mathrm{OH}$ emission may not reach the OI layer. Indeed, attempts to image green line structure during May and June when several of the $\mathrm{OH}$ wave patterns had significant eastward components of motion were unsuccessful. In comparison all but one of the wave patterns imaged in July exhibited strong northward motion (see Figure 7) which is the direction of least blocking at both the $\mathrm{OH}$ and the $\mathrm{OI}$ altitudes. Thus although limited, the $\mathrm{OI}$ data provide further support of wave filtering by winds.

The sources of the waves observed during this period are under investigation but are currently unknown. An unexpected consequence of this analysis points toward a tropospheric origin for the bulk of the wave motions. During the campaign, many thunderstorms were reported over Colorado and the neighboring states. Thunderstorm activity has been identified as a source of short-period gravity waves on at least one prior occasion [Taylor and Hapgood, 1988]. By comparing the properties of the image data with the distribution of thunderstorms and other tropospheric disturbances it may be possible to identify individual wave sources using the wind-filtering model.

The results of this study are quite remarkable when it is recalled that the blocking diagrams were developed using climatological data which provide only an estimate of the wave filtering to be expected at any given site for this time of the year. Ideally, for this type of investigation, simultaneous wind profile measurements should be made in the vicinity of the nightglow observations. The fact that the wave data collected over the 3-month period exhibited magnitudes and directions consistent with the model results suggests that climatological data are probably sufficient for this type of study. However, more measurements are needed before any firm conclusions can be drawn on this point. In particular, data taken during the winter months from a similar midlatitude site when the zonal winds blow toward the east (i.e., in the opposite direction to the summer flow) should provide a further important test for the theory.

\section{Summary}

The critical layer theory for gravity wave filtering has been applied to an extended set of nightglow measurements to study the effects of middle atmospheric winds on the propagation of short-period gravity waves. All-sky images of the NIR OH emissions are well suited for this research as they provide precise information on the directions of motion and the apparent speeds of the waves reaching the upper atmosphere. The measurements reported here show almost total agreement between the observed and the permitted wave azimuths and speeds. This result indicates that the flow of wave energy into the upper atmosphere can be significantly modified by the background winds. Whether wind filtering dominates the flux of short-period wave energy at other sites (at high, medium, and low latitudes) and times of the year has yet to be determined. If further nightglow measurements substantiate these findings, the wind-filtering model may be used to help make a more quantitative investigation of the dominant wave sources and to study regional and seasonal 
effects of short-period gravity waves on the dynamics of the upper atmosphere.

While one may well argue that only instantaneous wind profiles measured at the same time as the airglow data should be used, the combined data collected over 3 months, the general consistency between the forbidden region of the blocking diagrams and the observed gravity wave propagation directions as well as magnitudes, would all suggest that in the late spring and early summer months there may well be gravity wave (GW) directional filtering. Further verifications were found when the $\mathrm{OH}$ data taken by Lowe et al. on April 18, 1991, in London, Ontario, were checked with the blocking diagrams for London. The time of the year for this particular data set is of special interest. Obviously, more observations are needed before any firm conclusions can be drawn. Data taken during the winter when the zonal winds are blowing eastward (in the opposite direction) should give this theory a further important test.

We should mention that the filtering of a gravity wave through its absorption into the mean flow at the critical layer region applies only to stable background winds (i.e., the Richardson's number of the background winds is much greater than 1/4). For wind profiles with much steeper vertical gradients so that the background becomes unstable, reradiation and overreflection [Jones, 1968; Fritts, 1978; He et al., 1991] can occur. Under such circumstances the gravity wave blocking has to be entirely reexamined. However, in examining a large number of climatological background winds and atmospheric tides, we are unable to find much evidence for such steep vertical background wind gradients. It is always possible, of course, for instantaneous wind profiles, modified by long-period "background" gravity waves, to exhibit such background instability. But the overall consistency between the observed GW propagation and the blocking diagrams would suggest that the occurrence of such unstable background winds would be relatively rare.

Acknowledgments. We are most grateful to the director and staff of the Mountain Research Station of the University of Colorado for allowing us the use of their facilities for the optical measurements. We thank M. J. Hill (Southampton University) and P. Mace (Utah State University) for their considerable help during the campaign. We would like to thank E. A. Dewan, R. H. Picard, R. P. Lowe, and J. R. Winick for many helpful discussions on the gravity wave "blocking" model as well as the wind model. We would also like to thank R. Barnes of NCAR for his help with the Forbes/Vial Model Tides and to E. Fleming of Applied Research Corporation for supplying the climatological data as well as NCAR for the use of their CEDAR data base. This research was supported by the U.S. Air Force Office of Scientific Research (AFOSR) and the Phillips Laboratory under contract Fl9628-87K-0023 and Fl9628-91K-0024. The work was also supported by the ARC/AARC Airglow Modelling and the MAPSTAR program.

The Editor thanks C. G. Fesen and J. A. Waldock for their assistance in evaluating this paper.

\section{REFERENCES}

Adams, G. W., A. W. Peterson, J. W. Brosnahan, and J. W. Neuschaefer, Radar and optical observations of mesospheric wave activity during the lunar eclipse of 6 July 1982, J. Atmos. Terr. Phys., 50, 11, 1988.

Armstrong, E. B., Irregularities in the $80-$ to $100-\mathrm{km}$ region: A photographic approach, Radio Sci., 21, 313, 1986.

Baker, D. J., and A. T. Stair, Jr., Rocket measurements of the altitude distributions of the hydroxyl airglow, Phys. Scr., 37, 611, 1988.
Barnett, J. J., and M. Corney, Planetary waves, Middle Atmosphere Program, Map Handb., 16, 86, Sci. Comm. Sol. Terr. Phys. Secr., Univ. of Ill., Urbana, 1985.

Booker, J. R., and F. P. Bretherton, The critical layer for internal gravity waves in a shear flow, J. Fluid Mech., 27, 3, 513, 1967.

Chandra, S., E. Fleming, M. Schoeberl, and J. Barnett, Monthly mean global climatology of temperature, wind, geopotential height and pressure for 0-120 km, Adv. Space Res., 6, (6)3, 1990.

Chiu, Y. T., and L. R. Sharp, Correlative study of thermospheric gravity waves and tropospheric vorticity area index, Geophys. Res. Lett., 8, 281, 1981.

Clairemidi, J., M. Herse, and G. Moreels, Bi-dimensional observations of waves near the mesopuuse at auroral latitudes, Planet. Space Sci., 33, 1013, 1985.

Crawford, J., P. Rothwell, and M. J. Taylor, ASSESS 2: A simulated mission of Spacelab, Review article, Nature, 275, 17, 1978.

Fleming, E., and S. Chandra, Equatorial zonal wind in the middle atmosphere derived from geopotential height and temperature data, J. Atmos. Sci., 46(6), 860, 1989.

Fleming, E., S. Chandra, M. Shoeberl, and J. Barnett, Monthly mean global climatology of temperature, wind, geopotential height, and pressure for 0-120 km, NASA Tech. Memo. 100697, 1988.

Forbes, J. M., Atmospheric tides, 1, Model description and results for the solar diurnal component, J. Geophys. Res., 87(A7), 5222, $1982 a$.

Forbes, J. M., Atmospheric tides, 2, The solar and lunar semidiurnal components, J. Geophys. Res., 87(A7), 5241, $1982 b$.

Forbes, J. M., and D. F. Gillette, A compendium of theoretical atmospheric tidal structures, 1, Model description and explicit structures due to realistic thermal and gravitational excitation, Rep. AFGL-TR-82-0173(I), Air Force Geophys. Lab., Hanscom Air Force Base, Mass., 1982.

Forbes, J. M., and F. Vial, Monthly simulations of the solar semidiurnal tide in the mesosphere and lower thermosphere, $J$. Atmos. Terr. Phys., 5I(7/8), 649, 1989.

Francis, S. H., Global propagation of atmospheric gravity waves: A review, J. Atmos. Terr. Phys., 37, 1011, 1975.

Freund, J. T., and F. Jacka, Structure in the $557.7 \mathrm{~nm}(\mathrm{OI})$ airglow, J. Atmos. Terr. Phys., 41, 25, 1979.

Fritts, D. C., The nonlinear gravity wave-critical level interaction, J. Atmos. Sci., 35, 397, 1978.

Fritts, D. C., The excitation of radiating waves and KelvinHelmholtz instabilities by gravity wave-critical level interaction, J. Atmos. Sci., 36, 12, 1979.

Fritts, D. C., and M. A. Geller, Viscous stabilization of gravity wave critical level flows, J. Atmos. Sci., 33, 2276, 1976.

Fritts, D. C., and R. A. Vincent, Mesospheric momentum flux studies at Adelaide, Australia: Observations and a gravity wavetidal interaction model, J. Atmos. Sci., 44, 605, 1987.

Gavrilov, N. M., and G. M. Shved, Study of internal gravity waves in the lower thermosphere from observations of the nocturnal sky airglow [OI] 5577 Å in Ashkhadab, Ann. Geophys., 38, 789, 1982.

Hapgood, M. A., and M. T. Taylor, Analysis of airglow image data, Ann. Geophys., 38, 805, 1982.

Hazel, P., The effect of viscosity and heat conduction on internal gravity waves at a critical level, J. Fluid Mech., 30(4), 775, 1967.

He, F., T. F. Tuan, R. Picard, and J. Isler, Optical model analysis of gravity-wave reflections from critical layers, Eos Trans. AGU, $71,1496,1990$.

He, F., T. F. Tuan, R. Picard, and J. Isler, Modelling of optical model treatment of gravity-wave critical-layer interactions, Eos Trans. AGU, 72(17), Spring Meeting Suppl., 208, 1991.

Herse, M., Waves in the $\mathrm{OH}$ emissive layer, Science, 225, 172, 1984.

Hines, C. O., Internal atmospheric gravity waves, Can. J. Phys., 38, $1441,1960$.

Hines, C. O., A possible source of waves in noctilucent clouds, $J$. Atmos. Sci., 25, 937, 1968.

Hines, C. O., and C. A. Reddy, On the propagation of atmospheric gravity waves through regions of wind shear, J. Geophys. Res., $72,1015,1967$.

Hoffmeister, C., Investigations on bright night sky and luminous bands, J. Brit. Astron. Assoc., 62, 288, 1952.

Hung, R. J., T. Phan, and R. E. Simith, Coupling of ionosphere and 
troposphere during the occurrence of isolated tornadoes on November 20, 1973, J. Geophys. Res., 84, 1261, 1979.

Jones, W. L., Reflexion and stability of waves in stably stratified fluids with shear flow: A numerical study, J. Fluid Mech., 34(3), $609,1968$.

Krassovsky, V. I., and M. V. Shagaev, On the nature of internal gravity waves observed from hydroxyl emissions, Planet. Space Sci., 25, 200, 1977.

Lanchester, B. S., Relation between discrete auroral forms and magnetic field disturbances, $\mathrm{PhD}$. thesis, Univ. of Southampton, England, 1985.

Llewellyn, E. J., B. H. Long, and B. H. Solheim, The quenching of $\mathrm{OH}^{*}$ in the atmosphere, Planet. Space Sci., 26, 525, 1978.

Moreels, G., and M. Herse, Photographical evidence of waves around the $85 \mathrm{~km}$ level, Planet. Space Sci., 25, 265, 1977.

National Center for Atmospheric Research (NCAR) CEDAR Data Base Catalog, Forbes/Vial Model Tides 1988, Boulder, Colo., 1990.

Offermann, D., and A. Drescher, Atomic oxygen densities in the lower thermosphere as derived from in situ 5577- $\AA$ night airglow and mass spectrometer measurements, J. Geophys. Res., 78, $6690,1973$.

Peterson, A. W., Airglow events visible to the naked eye, Appl. Opt., 18, 3390, 1979.

Peterson, A. W., and L. M. Kieffaber, Infrared photography of $\mathrm{OH}$ airglow structures, Nature, 244, 92, 1973.

Röttger, J., Traveling disturbances in the equatorial ionosphere and their association with penetrative cumulus convection, J. Atmos. Terr. Phys., 39, 987, 1977.

Ryan, E. H., Critical layer directional filtering of atmospheric gravity waves: A comparison of airglow observation and a wind profile model, M.S. thesis, The Univ. of Cincinnati, Ohio, 1991.

Ryan, E. H., and T. F. Tuan, Gravity waves blocking by critical layers, in paper presented at Middle Atmosphere Periodic Structure and Associated Radiance (MAPSTAR) Meeting, Air Force Geophys. Lab., Boston, Mass., April 22-23, 1991.

Taylor, M. J., and R. Edwards, Observations of short period mesospheric wave patterns: In situ or tropospheric wave generation?, Geophys. Res. Lett., 18, 1337, 1991

Taylor, M. J., and M. A. Hapgood, Indentification of a thunderstorm as a source of short period gravity waves in the upper atmospheric nightglow emissions, Planet. Space Sci., 36(10), 975, 1988.

Taylor, M. J., and K. Henriksen, Gravity wave studies at polar latitudes, in Electromagnetic Coupling in the Polar Cleft and Caps, edited by P. E. Sandholt, and A. Egeland, Kluwer Academic Pub., Dordrecht, 421, 1989.

Taylor, M. J., and M. J. Hill, Near-infrared imaging of hydroxyl wave structure over an ocean site at low latitudes, Geophys. Res. Lett., 18, 1333, 1991.

Taylor, M. J., M. A. Hapgood, and P. Rothwell, Observations of gravity wave propagation in the OI $(557.7 \mathrm{~nm}), \mathrm{Na}(589.2 \mathrm{~nm})$ and the near infrared OH nightglow emissions, Planet. Space Sci., 35 , 413, 1987.

Taylor, M. J., P. J. Espy, D. J. Baker, R. J. Sica, P. C. Neal, and W. R. Pendelton, Jr., Simultaneous intensity, temperature, and imaging measurements of short period wave structure in the $\mathrm{OH}$ nightglow emission, Planet. Space Sci., 39, 1171, 1991a.

Taylor, M. J., D. N. Turnbull, and R. P. Lowe, Coincident imaging and spectrometric observations of zenith $\mathrm{OH}$ nightglow structure, Geophys. Res. Lett., 18, 1349, $1991 b$.

Wang, D. Y., and T. F. Tuan, Brunt-Doppler ducting of smallperiod gravity waves, J. Geophys. Res., 93(A9), 9916, 1988.

R. Edwards, Physics Department, The University of Southampton, Southampton, SO9 5NH, England.

E. H. Ryan and T. F. Tuan, Physics Department, University of Cincinnati, 400 Geology/Physics Building, Mail Location 11, Cincinnati, OH 45221-0011.

M. J. Taylor, Physics Department and Space Dynamics Laboratory, Utah State University, Logan, UT 84322.

(Received February 14, 1992;

revised October 26, 1992;

accepted October 27, 1992.) 